ORIGINAL

\title{
Clinical Significance of Vascular Endothelial Growth Factor Expression and Microvessel Density in Invasive Cervical Cancer
}

\author{
Yasuyo Saijo ${ }^{1}$, Hiroyuki Furumoto ${ }^{1,2}$, Kanako Yoshida' ${ }^{1}$ Masato Nishimura', and Minoru Irahara ${ }^{1}$ \\ ${ }^{1}$ Department of Obstetrics and Gynecology, Institute of Health Biosciences, the University of Tokushima Graduate School ; ${ }^{2}$ Department of Ob- \\ stetrics and Gynecology, Tokushima Red Cross Hospital, Tokushima, Japan
}

\begin{abstract}
To determine whether vascular endothelial growth factor (VEGF) expression and microvessel density are predictive of prognosis in cases of invasive cervical cancer, correlations among VEGF expression, microvessel density, and clinicopathological parameters were identified. VEGF expression was evaluated in 50 cervical cancer samples by immunohistochemical staining. Microvessel density was assessed by immunostaining for CD31 - positive endothelial cells in the most vascularized areas of tumors. VEGF expression and microvessel density were significantly higher in adenocarcinomas than in squamous cell carcinomas. However, in cases of adenocarcinoma, no significant correlations were found among VEGF expression, microvessel density, and clinicopathological parameters. In contrast, for squamous cell carcinomas, microvessel density was significantly higher in cases at an advanced stage and in those with several other poor prognostic factors. The finding that cervical adenocarcinomas exhibited greater VEGF expression and microvessel density than squamous cell carcinomas may explain the poorer prognosis of adenocarcinoma compared with squamous cell carcinoma. Moreover, microvessel density in squamous cell carcinomas was significantly correlated with poor prognostic factors. Therefore, there is possibility that bevacizumab, a humanized monoclonal antibody against VEGF-A, may be useful in the initial treatment targeting angiogenesis for early-stage cervical cancer. J. Med. Invest. 62 : 154 160, August, 2015
\end{abstract}

Keywords : cervical cancer, vascular endothelial growth factor, microvessel density, bevacizumab, angiogenesis

\section{INTRODUCTION}

Cervical cancer is still associated with high mortality rates among women worldwide (1). Tumor neovascularization plays a crucial role in the development of solid tumors including cervical cancers. Vascular endothelial growth factor (VEGF) is a potent mitogen responsible for the induction of angiogenesis (2). VEGF mRNA expression and microvessel density are significantly increased in invasive carcinomas and high-grade intraepithelial lesions compared with low-grade intraepithelial and benign squamous epithelium lesions (3). High microvessel density is also significantly associated with increased VEGF mRNA expression.

In cases of advanced stage cervical cancer, there are no significant correlations between VEGF mRNA expression and prognostic factors including histological type and lymph node metastasis, although a significant relationship between VEGF mRNA expression and microvessel density was observed (4). Furthermore, no significant correlation could be demonstrated between VEGF expression and clinicopathological parameters in cases of cervical cancer (5). However, several studies have demonstrated that increased microvessel density and VEGF expression are significantly correlated with poorer prognosis in cases of cervical cancer (6-9).

Bevacizumab, an antibody targeting VEGF, exhibits antitumor properties by inhibiting angiogenesis. Currently, it is used as an effective drug in the treatment of lung, colorectal, and ovarian cancers. Recent research has focused on the effect of bevacizumab

Received for publication December 5, 2014 ; accepted February 17, 2015.

Address correspondence and reprint requests to Yasuyo Saijo, MD, Department of Obstetrics and Gynecology, Institute of Health Biosciences, the University of Tokushima Graduate School, 3-18-15 Kuramoto-cho, Tokushima 770-8503, Japan and Fax : +81-88-631-2630. against cervical cancer. In the GOG 240 trial, bevacitumab significantly improved the overall survival when added to chemotherapy for patients with persistent, recurrent, or metastatic cervical cancer (10). Moreover, the U.S. Food and Drug Administration (FDA) has approved bevacizumab for use in the patients with aggressive and late-stage cervical cancer (11). Although VEGF can be a target in the treatment of cervical cancer, it is unclear in which cases bevacizumab will be the most effective. Therefore, we investigated potential correlations among VEGF expression, microvessel density, and clinicopathological features in this study to determine whether VEGF expression and microvessel density in invasive cervical cancer lesions are predictive of prognosis.

\section{MATERIALS AND METHODS}

Clinical materials

Fifty samples of invasive uterine cervical cancer tissues were obtained from 26-70-years-old patients who provided informed consent. The patients underwent surgical treatment at the Tokushima University Hospital between 1998 and 2002. Tissue sections were fixed in paraformaldehyde and embedded in paraffin for histopathological examination and immunohistochemical staining. All cases were staged according to the 1994 International Federation of Gynecology and Obstetrics criteria as follows : two patients were stage Ia, 30 were stage Ib, five were stage IIa, and 13 were stage IIb. Tumors were classified histologically on the basis of the World Health Organization criteria as follows : 32 squamous cell carcinomas, 17 adenocarcinomas, and one adenosquamous carcinoma.

\section{Immunohistochemistry}

Tissue sections of $4-\mu \mathrm{m}$ thickness were cut, dried overnight at 
$40^{\circ} \mathrm{C}$ on poly-L-lysine-coated slides, deparaffinized, and rehydrated. The methods used for antigen retrieval are described in Table 1. After washing with distilled water, the slides were incubated for 10 min in 3\% hydrogen peroxide to inactivate endogenous peroxidase activity. We stained the tissue sections according to the standard avidin-biotin-peroxidase complex method using a LSAB2 Kit employing peroxidase (Dako, Glostrup, Denmark). After incubation for 10 min with $0.25 \%$ casein in phosphate-buffered saline (PBS) containing carrier protein to eliminate nonspecific background staining, the slides were covered with primary antibody solution and incubated for $120 \mathrm{~min}$ at room temperature. The primary antibodies used are listed in Table 1 . After washing with Tris-buffered saline (TBS) containing $0.1 \%$ Tween 20 (TTBS), the slides were incubated for 30 min with a solution containing biotinylated antimouse and anti-rabbit immmunoglobulin $\mathrm{G}$ at room temperature. They were then incubated in peroxidase-conjugated avidin solution for $20 \mathrm{~min}$ and washed with TTBS. Color was developed using diaminobenzidine, and counterstaining was performed with Mayer's hematoxylin. The positive control treatments for VEGF (12) are described in Table 1. Samples treated with normal serum in place of primary antibodies served as the negative control. VEGF staining specificity was confirmed by the preabsorption of the primary antibody with VEGF peptides (Fig. 1).

\section{Semiquantification of immunostaining results}

The immunostained sections were semiquantitatively evaluated

Table 1. Immunostaining : Antigen retrieval, Primary antibody, and Positive control

\begin{tabular}{cl}
\hline \multicolumn{2}{c}{ Antigen retrieval } \\
\hline VEGF & $\begin{array}{l}0.4 \% \text { pepsin in } 0.2 \mathrm{M} \mathrm{HCl} \text { solution, } 37^{\circ} \mathrm{C}, 15 \mathrm{~min} \\
\text { CD31 } \\
\text { proteinase K, room temperature, } 8 \mathrm{~min} \text { (Dako, Glostrup, } \\
\text { Denmark) }\end{array}$ \\
\hline Primary antibody \\
\hline VEGF & $\begin{array}{l}\text { rabbit anti-human VEGF (C-1), } \\
\text { monoclonal, at } 15 \mu \mathrm{g} / \mathrm{mL} \text { (Santa Cruz Biotechnology, } \\
\text { Santa Cruz, CA, USA) } \\
\text { mouse anti-human CD31, } \\
\text { monoclonal (clone JC70A, prediluted : Dako, Glostrup, } \\
\text { Denmark) }\end{array}$ \\
\hline Positive control \\
\hline VEGF & normal placenta \\
\hline
\end{tabular}

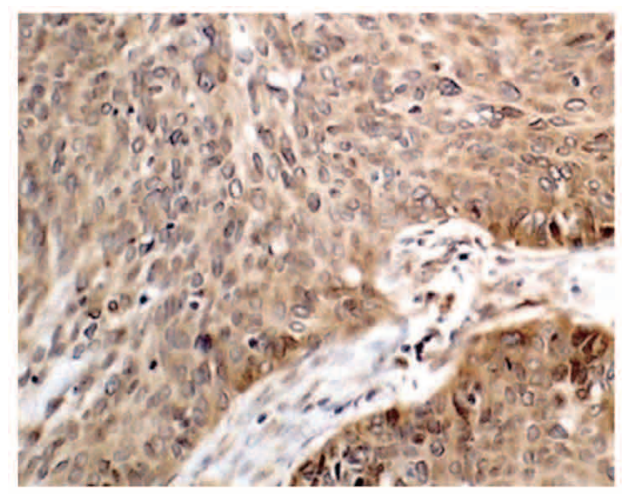

A by investigators who had no knowledge of the clinical status of the patient. VEGF expression in tumor cells was evaluated as previously described $(13,14)$. After screening each section as a whole, microscopic fields were selected using a random point grid and the mean percentage of specifically brown immunostained tumor cell areas in five microscopic fields at $200 \times$ magnification $\left(1.33 \mathrm{~mm}^{2}\right.$ per field $)$ was determined. The scores were as follows : $0 \%=0 ; 1-25 \%=1$; $26-50 \%=2 ; 51-75 \%=3$; and $76-100 \%=4$. The mean intensities of the immunostained areas based on the arbitrary numerical values were recorded as follows : none $=0$; weak $=1$; moderate $=2$; and strong $=3$. We judged that moderate staining was comparable to the staining intensity observed for positive control sections (Figs. 2 and 3). To obtain semiquantitative values for VEGF antigens per tissue, the score for the percentage of positively stained cells and intensity of the staining obtained for each section were multiplied (range, 0-12) and the overall antigen expression was categorized as follows : 0 , negative ; $1-4$, low ; and $6-12$, high.

\section{Microvessel density}

According to a previously described method, the sections were scanned at low magnification $(40-100 \times)$ to identify the most vascularized areas within the tumor samples (15). Within these areas, microvessels were counted in a $200 \times$ magnified field. Any area of brown-stained endothelial cells that was clearly separated from the adjacent microvessels, tumor cells, and other connective tissue elements was considered a single countable microvessel. Microvessel density was calculated by adding the numbers of microvessels in 15 fields for each sample.

\section{Statistical analysis}

Statistical analysis was performed using Mann-Whitney U tests and Fisher's exact probability tests. The correlation between VEGF expression and microvessel density was examined using the Spearman's rank correlation test. The Kaplan-Meier method and log rank tests were used to clarify whether VEGF expression and microvessel density are predictive of prognosis in cases of cervical cancer.

\section{RESULTS}

\section{Correlations between VEGF expression and clinicopathological} parameters

VEGF expression was observed in all 50 samples (Figs. 3A, B). The average semiquantitative VEGF expression values in cases of squamous cell carcinoma and adenocarcinoma were $4.4 \pm 1.8$ and

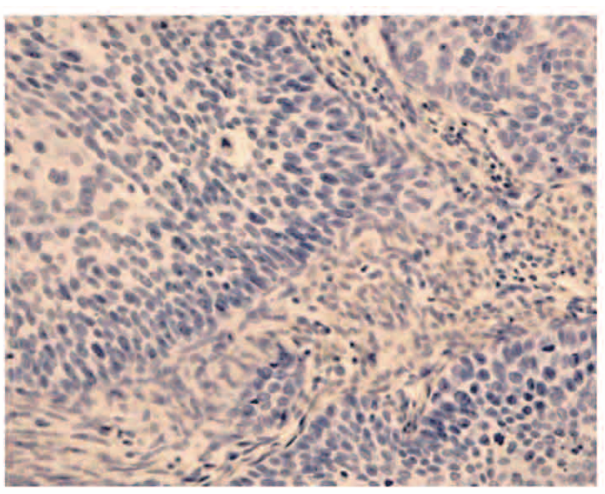

B

Figure 1. Antibody absorption test using VEGF peptides

The specificity of immunostaining was confirmed by testing absorption between the primary antibody and VEGF peptides. (A) Positive staining for VEGF, (B) staining of VEGF absorbed to VEGF peptides. Magnification, 200× in (A), (B). 


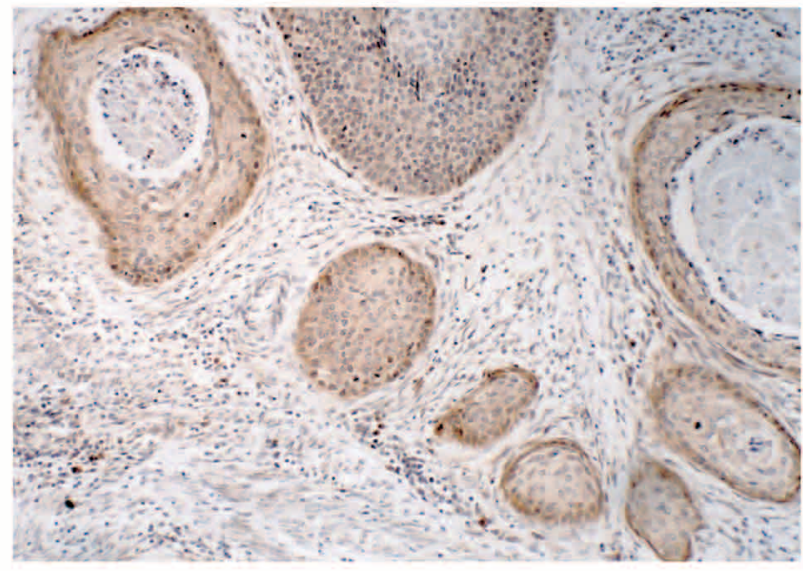

A

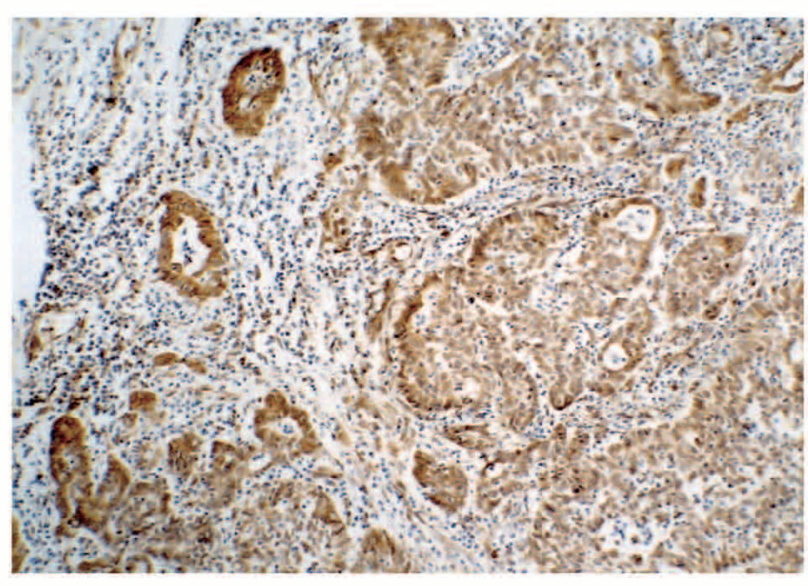

B

Figure 2. Representative examples of VEGF immunostaining The intensity of immunostaining was semiquantified as none $: 0$, weak : 1 , moderate : 2 , and strong : 3 . (A) Typical example of weak staining (squamous cell carcinoma), and (B) typical example of moderate staining (adenocarcinoma). Magnification, $100 \times$.

$7.3 \pm 1.8$, respectively, and VEGF expression was significantly higher in adenocarcinomas than in squamous cell carcinomas $(\mathrm{P}<$ 0.001 ; Table 2). In addition, elevated VEGF expression was observed in a significantly larger proportion of adenocarcinomas compared with squamous cell carcinomas [ $88.24 \%$ (15 cases) vs. $18.75 \%$ (6 cases), $\mathrm{P}<0.001$; Table 3]. However, there were no significant correlations between VEGF expression and the assessed clinicopathological parameters (Table 4).

Table 2. VEGF expression and microvessel density by histological types

\begin{tabular}{lcc}
\hline & VEGF expression score & Microvessel density \\
\hline $\begin{array}{c}\text { Squamous cell carcinoma } \\
(\mathrm{n}=32)\end{array}$ & $4.4 \pm 1.8$ & $488.6 \pm 189.4$ \\
$\begin{array}{c}\text { Adenocarcinoma } \\
(\mathrm{n}=17)\end{array}$ & $7.3 \pm 1.8$ & $678.5 \pm 242.5$ \\
& $\mathrm{P}<0.001^{*}$ & $\mathrm{P}=0.013^{\star}$ \\
\hline
\end{tabular}

*Mann-Whitney's U test $(\mathrm{P}<0.05)$

Data are presented as mean \pm standard deviation.
Table 3. VEGF expression score by histological types

\begin{tabular}{lcc}
\hline & \multicolumn{2}{c}{ VEGF expression score } \\
& Low & High \\
& (score 1-4) & (score 6-12) \\
\hline Squamous cell carcinoma & 26 cases & 6 cases \\
$(\mathrm{n}=32)$ & $(81.25 \%)$ & $(18.75 \%)$ \\
Adenocarcinoma & 2 cases & 15 cases \\
$(\mathrm{n}=17)$ & $(11.76 \%)$ & $(88.24 \%)$ \\
& & $\mathrm{P}<0.001^{\star}$ \\
\hline
\end{tabular}

${ }^{\star}$ Fisher's exact probability test $(\mathrm{P}<0.05)$

Correlations between microvessel density and clinicopathological parameters

Microvessel density was evaluated by detecting CD31-positive cells and counting the corresponding vessels (Figs. 3D, E). Microvessel density was significantly greater in adenocarcinoma samples than that in squamous cell carcinoma samples $(P=0.013$; Table 2). In cases of adenocarcinoma, no significant correlations were observed between microvessel density and the assessed clinicopathological parameters. In contrast, microvessel density was significantly greater in squamous cell carcinoma samples than that in advanced stage carcinoma samples and in those with deeper myometrial invasion, vaginal involvement, lymph node metastasis, lymphovascular space invasion, and a high recurrence rate (Table 5).

Correlations among VEGF expression, microvessel density, and prognosis

A weak but significant correlation was observed between VEGF expression and microvessel density (data not shown). Using the Kaplan-Meier method and log rank tests, no significant correlations were observed between VEGF expression and overall survival or disease-free survival or between microvessel density and overall or disease-free survival. These same results were obtained for both adenocarcinoma and squamous cell carcinoma (data not shown).

\section{DISCUSSION}

Angiogenesis plays a key role in tumor growth and metastasis. Although angiogenic factor expression and microvessel density have been reported to be markers of tumor malignancy, their utility in cervical cancer remains controversial. A significant correlation was reported between VEGF protein expression and prognostic factors in cervical cancer lesions (6). However, another study reported no significant correlations between VEGF mRNA expression levels and prognostic factors in cervical cancer tissues (4). The correlation between microvessel density and cervical cancer prognosis is also controversial. Several studies have demonstrated that high microvessel density is a useful indicator of cervical cancer prognosis $(16,17)$. Randall et al. reported that increased tumor angiogenesis measured according to CD31-positive microvessel density is an independent prognostic marker of improved progression-free and overall survival. They hypothesized that increased microvessel density is associated with improved treatment response due to better chemotherapeutic delivery and enhanced radiation therapy in well-oxygenated tumors (18). Cervical adenocarcinoma is associated with lower survival compared with squamous cell carcinoma (19-21). Another study reported that microvessel density and VEGF mRNA expression were significantly higher in cervical adenocarcinoma than in squamous cell carcinoma, although no 

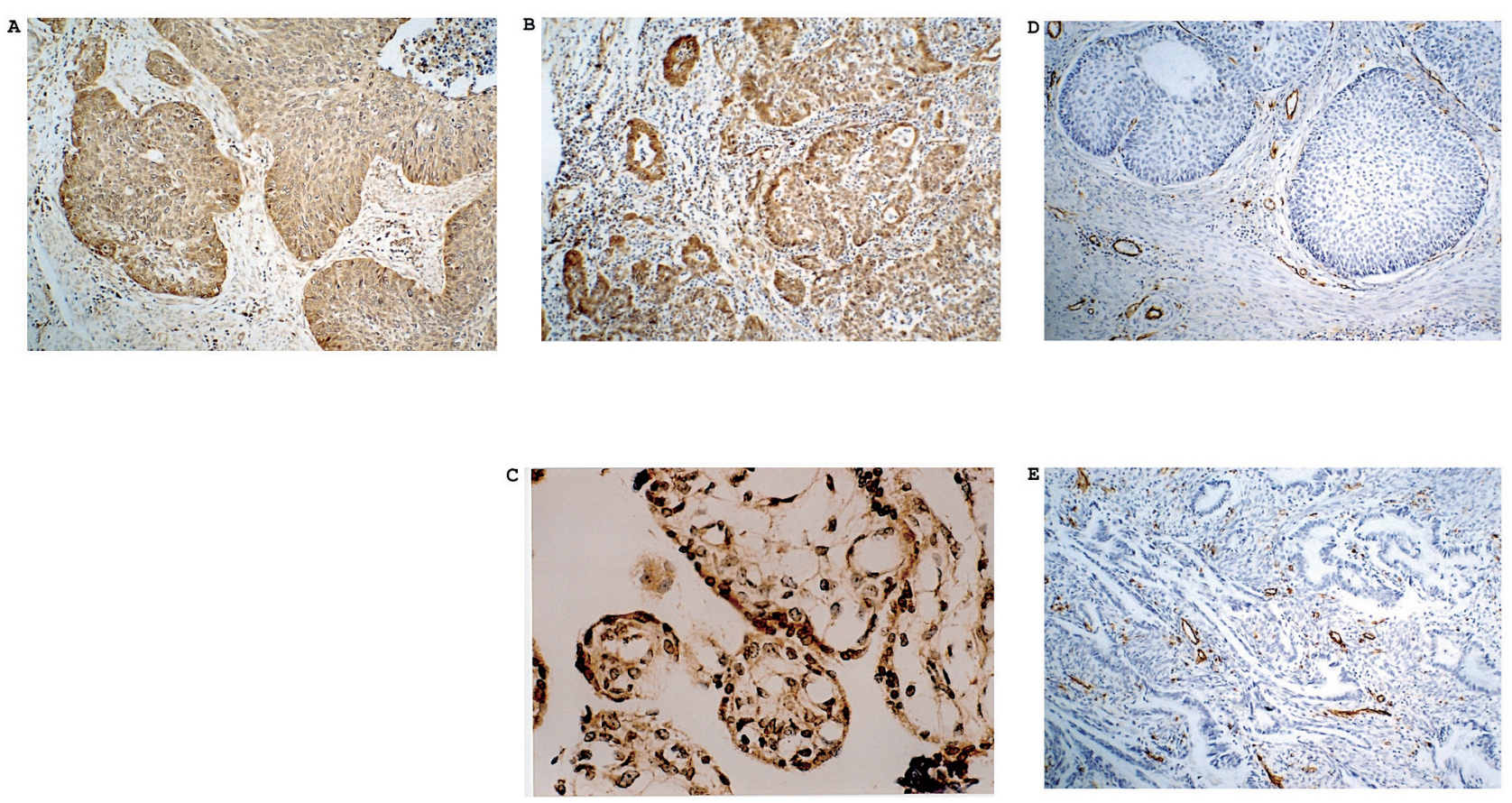

Figure 3. Immunohistochemical staining for VEGF in squamous cell carcinoma (A), in adenocarcinoma (B), in normal placenta as a positive control (C), and staining for CD31 in squamous cell carcinoma (D) and adenocarcinoma (E). VEGF expression and microvessel density were significantly greater in adenocarcinomas than in squamous cell carcinomas. Magnification, $100 \times$ in (A), (B), (D), (E) and 400× in (C).

Table 4. Clinicopathological parameters and VEGF expression score (mean \pm S.D.)

\begin{tabular}{|c|c|c|c|c|c|c|}
\hline \multirow[b]{2}{*}{ Valiable } & \multicolumn{3}{|c|}{ Squamous cell carcinoma } & \multicolumn{3}{|c|}{ Adenocarcinoma } \\
\hline & $\mathrm{n}$ & VEGF expression score & P value ${ }^{*}$ & $\mathrm{n}$ & VEGF expression score & Pvalue $^{*}$ \\
\hline \multicolumn{7}{|c|}{ Stage (FIGO) } \\
\hline I & 19 & $3.9 \pm 1.4$ & NS & 13 & $7.6 \pm 1.4$ & NS \\
\hline II & 13 & $5.1 \pm 2.1$ & & 4 & $6.5 \pm 3.0$ & \\
\hline \multicolumn{7}{|c|}{ Cervical infiltration depth } \\
\hline$<2 / 3$ & 13 & $4.6 \pm 1.9$ & NS & 9 & $7.4 \pm 1.8$ & NS \\
\hline$\geqq 2 / 3$ & 19 & $4.0 \pm 1.7$ & & 8 & $7.3 \pm 2.0$ & \\
\hline \multicolumn{7}{|c|}{ Parametrial involvement } \\
\hline Positive & 7 & $4.9 \pm 2.3$ & NS & 4 & $8.0 \pm 0$ & NS \\
\hline Negative & 25 & $4.2 \pm 1.7$ & & 13 & $7.2 \pm 2.1$ & \\
\hline \multicolumn{7}{|c|}{ Vaginal involvement } \\
\hline Positive & 9 & $4.6 \pm 2.2$ & NS & 6 & $7.0 \pm 2.4$ & NS \\
\hline Negative & 23 & $4.3 \pm 1.7$ & & 11 & $7.5 \pm 1.5$ & \\
\hline \multicolumn{7}{|c|}{ Pelvic lymph node metastasis } \\
\hline Positive & 11 & $4.2 \pm 1.4$ & NS & 4 & $8.0 \pm 0$ & NS \\
\hline Negative & 21 & $4.5 \pm 2.0$ & & 13 & $7.2 \pm 2.1$ & \\
\hline \multicolumn{7}{|c|}{ Lymphovascular permeation } \\
\hline Positive & 22 & $4.2 \pm 1.7$ & NS & 9 & $7.4 \pm 1.7$ & NS \\
\hline Negative & 10 & $4.7 \pm 2.1$ & & 8 & $7.3 \pm 2.1$ & \\
\hline \multicolumn{7}{|l|}{ Recurrence } \\
\hline Yes & 7 & $4.6 \pm 1.5$ & NS & 4 & $8.0 \pm 0$ & NS \\
\hline No & 25 & $4.3 \pm 1.9$ & & 13 & $7.2 \pm 2.1$ & \\
\hline
\end{tabular}

*Mann-Whitney's U test $(\mathrm{P}<0.05)$ 
Table 5. Clinicopathological parameters and microvessel density (mean \pm S.D.)

\begin{tabular}{|c|c|c|c|c|c|c|}
\hline \multirow[b]{2}{*}{ Valiable } & \multicolumn{3}{|c|}{ Squamous cell carcinoma } & \multicolumn{3}{|c|}{ Adenocarcinoma } \\
\hline & $\mathrm{n}$ & Microvessel density & Pvalue ${ }^{*}$ & $\mathrm{n}$ & Microvessel density & Pvalue $^{*}$ \\
\hline \multicolumn{7}{|c|}{ Stage (FIGO) } \\
\hline I & 19 & $441.3 \pm 198.4$ & 0.043 & 13 & $705.4 \pm 249.0$ & NS \\
\hline II & 13 & $557.8 \pm 158.0$ & & 4 & $591.0 \pm 228.6$ & \\
\hline \multicolumn{7}{|c|}{ Cervical infiltration depth } \\
\hline$<2 / 3$ & 13 & $376.4 \pm 165.5$ & 0.004 & 9 & $629.0 \pm 264.5$ & NS \\
\hline$\geqq 2 / 3$ & 19 & $565.4 \pm 168.0$ & & 8 & $734.1 \pm 218.5$ & \\
\hline \multicolumn{7}{|c|}{ Parametrial involvement } \\
\hline Positive & 7 & $588.7 \pm 183.4$ & NS & 4 & $646.5 \pm 173.0$ & NS \\
\hline Negative & 25 & $460.6 \pm 185.0$ & & 13 & $688.3 \pm 265.4$ & \\
\hline \multicolumn{7}{|c|}{ Vaginal involvement } \\
\hline Positive & 9 & $598.0 \pm 132.2$ & 0.023 & 6 & $582.5 \pm 177.7$ & NS \\
\hline Negative & 23 & $445.8 \pm 193.4$ & & 11 & $730.8 \pm 264.1$ & \\
\hline \multicolumn{7}{|c|}{ Pelvic lymph node metastasis } \\
\hline Positive & 11 & $624.0 \pm 161.1$ & 0.005 & 4 & $743.8 \pm 290.9$ & NS \\
\hline Negative & 21 & $417.7 \pm 165.2$ & & 13 & $658.4 \pm 253.3$ & \\
\hline \multicolumn{7}{|c|}{ Lymphovascular permeation } \\
\hline Positive & 22 & $542.1 \pm 187.8$ & 0.015 & 9 & $693.2 \pm 236.3$ & NS \\
\hline Negative & 10 & $371.0 \pm 137.3$ & & 8 & $661.9 \pm 264.5$ & \\
\hline \multicolumn{7}{|l|}{ Recurrence } \\
\hline Yes & 7 & $650.7 \pm 189.0$ & 0.027 & 4 & $774.8 \pm 269.5$ & NS \\
\hline No & 25 & $443.2 \pm 166.2$ & & 13 & $648.8 \pm 237.1$ & \\
\hline
\end{tabular}

*Mann-Whitney's U test $(\mathrm{P}<0.05)$

prognostic significance could be demonstrated for microvessel density or VEGF expression (22). In the present study, we observed a significant correlation between VEGF expression and microvessel density and both were significantly higher in adenocarcinoma samples than in squamous cell carcinoma samples. These findings may explain the aggressive behavior of adenocarcinomas. Moreover, in cases of squamous cell carcinoma, microvessel density was significantly greater in the presence of poor prognostic factors, including advanced stage carcinoma, deeper myometrial invasion, vaginal involvement, lymph node metastasis, lymphovascular space invasion, and a high recurrence rate. However, no significant correlations were observed between these factors in cases of adenocarcinoma. One explanation for this discrepancy is that the number of adenocarcinoma samples $(n=17)$ was too small to yield significant results. Another possibility is that most cases of adenocarcinoma demonstrated high VEGF expression levels and high microvessel density, making it difficult to detect differences with statistical significance.

Currently, the optimal treatment strategy for stage Ib-IIb early cervical cancer remains unknown. Many countries accept concurrent radiotherapy (CCRT) as a standard initial treatment, and it is sometimes used postoperatively as well (23-26). Radiotherapy (RT) is becoming somewhat indispensable but for maximizing the long-term quality of life of a patient with cervical cancer, the typical late side effects of RT, such as lower extremity edema and gastrointestinal obstruction, must be considered and minimized. Cervical cancer treatment requires adjustments according to the circumstances of each case, and such adjustments can include avoiding $\mathrm{RT}$ as an initial treatment, performing surgery after a preoperative course of neoadjuvant chemotherapy, selecting chemotherapy (CT) for postoperative treatment, and resorting to RT in cases of subsequent recurrence of localized cancer within the pelvis. Using these treatment approaches, a favorable progression-free survival rate was reported for the treatment of patients with stage Ib2-IIb cervical cancer (27).

For cervical adenocarcinoma, there is no solid evidence regarding the most effective treatment approach (28). Many studies report that the use of RT within the pelvis is more effective for suppressing squamous cell carcinoma than adenocarcinoma (29-32). A recent study reported no appreciable difference in the 5-year survival rate when RT, including CCRT, was compared with CT alone in the postoperative treatment of stages Ib-IIb cervical adenocarcinoma (33). Thus, avoiding RT and applying surgery and CT in treating early cervical adenocarcinoma should be thoroughly considered.

Bevacizumab (Avastin $\AA$ ), a humanized monoclonal antibody directed against VEGF-A, has been reported to be effective in cases of recurrent squamous cell carcinoma of uterine cervix (34). In the present study, squamous cell carcinoma tissues clearly exhibited high microvessel density, suggesting the potential applicability of bevacizumab. In addition, VEGF expression in adenocarcinoma was significantly greater than that in squamous cell carcinoma along with a high microvessel density, which further indicates the potential effectiveness of bevacizumab for treating adenocarcinoma. In 
August 2014, the FDA approved bevacizumab for cervical cancer treatment in cases of recurrence or progression (11). Because increased VEGF expression was observed in this study in cases of early invasive cancer (stage I and II), targeting angiogenesis as an initial strategy in cervical cancer treatment appears promising and raises new expectations for improvements in long-term survival among patients with a condition for which such expectations have not existed for many years.

\section{REFERENCES}

1. Bosch FX, Lorincz A, Munoz N, Meijer CJ, Shah KV : The causal relation between human papilloma virus and cervical dysplasia. J Clin Pathol 55(4) : 244-265, 2002

2. Ferrara $\mathrm{N}$ : Molecular and biological properties of vascular endothelial growth factor. J Mol Med 77(7) : 527-543, 1999

3. Guide AJ, Jawdeh GA, Berse B, Jackman RW, Tognazzi K, Dvorak HF, Brown LF : Vascular permeability factor (vascular endothelial growth factor) expression and angiogenesis in cervical neoplasia. J Natl Cancer Inst 87 (16) : 1237-1245, 1995

4. Kodama J, Seki N, Tokumo K, Hongo A, Miyagi Y, Yoshinouchi M, Okuda H, Kudo T : Vascular endothelial growth factor is implicated in early invasion in cervical cancer. Eur J Cancer 35(3) : 485-489, 1999

5. Tjalma W, Weyler J, Weyn B, Van Marck E, Van Daele A, VanDam P, Goovaerts G, Buytaert P: The association between vascular endothelial growth factor, microvessel density and clinicopathological features in invasive cervical cancer. Eur J Obstet Gynecol Reprod Biol 92(2) : 251-257, 2000

6. Cheng WF, Chen CA, Lee CN, Wei LH, Hsieh FJ, Hsieh CY : Vascular endothelial growth factor and prognosis of cervical carcinoma. Obstet Gynecol 96(5 Pt 1) : 721-726, 2000

7. Bremer GL, Tiebosch ATMG, van der Putten HWHM, Schouten HJA, de Haan J, Arends JW : Tumor angiogenesis : an independent prognostic parameter in cervical cancer. Am J Obstet Gynecol 174(1 Pt 1) : 126-131, 1996

8. Dinh TV, Hannigan EV, Smith ER, Hove MJ, Chopra V, To T : Tumor angiogenesis as a predictor of recurrence in stage $\mathrm{Ib}$ squamous cell carcinoma of the cervix. Obstet Gynecol 87(5 Pt 1) : 751-754, 1996

9. Wiggins DL, Granai CO, Steinhoff MM, Calabresi P : Tumor angiogenesis as a prognostic factor in cervical carcinoma. Gynecol Oncol 56(3) : 353-356, 1995

10. Tewari KS, Sill MW, Long HJ 3rd, Penson RT, Huang H, Ramondetta LM, Landrum LM, Oaknin A, Reid TJ, Leitao MM, Michael HE, Monk BJ : Improved survival with bevacizumab in Advanced cervical cancer. N Engl J Med 370(8) : 734-743, 2014

11. Media Release. FDA approves Roche's Avastin plus for treatment of advanced cervical cancer. Avastin is the first biologic medicine approved in combination with chemotherapy to help women with this type of cancer live longer than with chemotherapy alone : F. Hoffmann-La Roche Ltd. 15 August 2014.

12. Shiraishi S, Kinukawa N, Nakano H, Sueishi K: Immunohistochemical distribution of vascular endothelial growth factor in the human placenta associated with hydrops fetalis. Pediatr Pathol Lab Med 17(1) : 65-81, 1997

13. Shen GH, Ghazizadeh M, Kawanami O, Shimizu H, Jin E, Araki T, Sugisaki Y : Prognostic significance of vascular endothelial growth factor expression in human ovarian carcinoma. Br J Cancer 83(2) : 196-203, 2000

14. Ghazizadeh M, Ogawa H, Sasaki Y, Araki T, Aihara K : Mucin carbohydrate antigens ( $\mathrm{T}, \mathrm{Tn}$, and sialyl-Tn) in human ovarian carcinomas : relationship with histopathology and prognosis. Hum Pathol 28(8) : 960-966, 1997
15. Weidner N, Semple JP, Welch WR, Folkman J : Tumor angiogenesis and metastasis-correlation in invasive breast carcinoma. N Engl J Med 324(1) : 1-8, 1991

16. Rutgers JL, Mattox TF, Vargas MP : Angiogenesis in uterine cervical squamous cell carcinoma. Int J Gynecol Pathol 14(2) : 114-118, 1995

17. Kainz C, Speiser P, Wanner C, Obermair A, Tempfer C, Sliutz G, Reinthaller A, Breitenecker G : Prognostic value of tumour microvessel density in cancer of the uterine cervix stage IB to IIB. Anticancer Res 15(4) : 1549-1551, 1995

18. Randall LM, Monk BJ, Darcy KM, Tian C, Burger RA, Liao SY, Peters WA, Stock RJ, Fruehauf JP : Markers of angiogenesis in high-risk, early-stage cervical cancer : A Gynecologic Oncology Group study. Gynecol Oncol 112(3) : 583-589, 2008

19. Lee YY, Choi CH, Kim TJ, Lee JW, Kim BG : A comparison of pure adenocarcinoma and squamous cell carcinoma of the cervix after radical hysterectomy in stage IB-IIA. Gynecol Oncol 120(3) : 439-443, 2011

20. Burke TW, Hoskins WJ, Heller PB, Shen MC, Weiser EB, Park RC : Clinical patterns of tumor recurrence after radical hysterectomy in stage IB cervical carcinoma. Obstet Gynecol $69: 382-385,1987$

21. Huang HJ, Chang TC, Hong JH, Tseng CJ, Chou HH, Huang KG, Lai CH : Prognostic value of age and histologic type in neoadjuvant chemotherapy plus radical surgery for bulky ( $\geqq 4 \mathrm{~cm}$ ) stage IB and IIA cervical carcinoma. Int J Gynecol Cancer $13: 204-211,2003$

22. Tokumo K, Kodama J, Seki N, Nakanishi Y, Miyagi Y, Kamimura S, Yoshinouchi M, Okuda H, Kudo T : Different angiogenic pathways in human cervical cancers. Gynecol Oncol 68(1) : 38-44, 1998

23. Chemoradiotherapy for Cervical Cancer Meta-Analysis Collaboration : Reducing uncertainties about the effects of chemoradiotherapy for cervical cancer : a systematic review and metaanalysis of individual patient data from 18 randomized trials. J Clin Oncol 26(35) : 5802-5812, 2008

24. Petsuksiri J, Chansilpa Y, Therasakvichya S, Suntornpong N, Thephamongkhol K, Dankulchai P, Mahasitthiwat P, Ieumwananonthachai N, Veerasarn V, Sangruchi S, Pattaranutaporn $\mathrm{P}$ : Treatment options in bulky stage IB cervical carcinoma. Int J Gynecol Cancer 18(6) : 1153-1162, 2008

25. Peters WA 3rd, Liu PY, Barrett RJ 2nd, Stock RJ, Monk BJ, Berek JS, Souhami L, Grigsby P, Gordon W Jr, Alberts DS : Concurrent chemotherapy and pelvic radiation therapy compared with pelvic radiation therapy alone as adjuvant therapy after radical surgery in high-risk early-stage cancer of the cervix. J Clin Oncol 18(8) : 1606-1613, 2000

26. Monk BJ, Wang J, Im S, Stock RJ, Peters WA 3rd, Liu PY, Barrett RJ 2nd, Berek JS, Souhami L, Grigsby PW, Gordon W Jr, Alberts DS ; Gynecologic Oncology Group ; Southwest Oncology Group ; Radiation Therapy Oncology Group : Rethinking the use of radiation and chemotherapy after radical hysterectomy : a clinical-pathologic analysis of a Gynecologic Oncology Group/Southwest Oncology Group/Radiation Therapy Oncology Group trial. Gynecol Oncol 96(3) : 721-728, 2005

27. Matsumura M, Takeshima N, Ota T, Omatsu K, Sakamoto K, Kawamata Y, Umayahara K, Tanaka H, Akiyama F, Ken Takizawa K : Neoadjuvant chemotherapy followed by radical hysterectomy plus postoperative chemotherapy but no radiotherapy for Stage IB2-IIB cervical cancer-irinotecan and platinum chemotherapy. Gynecol Oncol 119(2) : 212-216, 2010

28. Diagnosis and treatment of cervical carcinomas. ACOG Practice Bulletin No 35, May 2002

29. Rombaut RP, Charles D, Murphy A : Adenocarcinoma of the cervix. A clinicopathologic study of 47 cases. Cancer 19 : 
891-900, 1966

30. Wheeless CR Jr, Graham R, Graham JB : Prognosis and treatment of adenoepidermoid carcinoma of the cervix. Obstet Gynecol 35 : 928-932, 1970

31. Rutledge FN, Galakatos AE, Wharton JT, Smith JP : Adenocarcinoma of the uterine cervix. Am J Obstet Gynecol 122 : 236-245, 1975

32. Berek JS, Castaldo TW, Hacker NF, Petrilli ES, Lagasse LD, Moore JG : Adenocarcinoma of the uterine cervix. Cancer 48 : 2734-2741, 1981

33. Shimada M, Nishimura R, Hatae M, Hiura M, Takehara K,
Tase T, Yamada H, Kurachi H, Sugiyama T, Kigawa J : Comparison of adjuvant chemotherapy and radiotherapy in patients with cervical adenocarcinoma of the uterus after radical hysterectomy : SGSG/TGCU Intergroup surveillance. Eur J Gynaecol Oncol 34(5) : 425-428, 2013

34. Monk BJ, Sill MW, Burger RA, Gray HJ, Buekers TE, Roman $\mathrm{LD}$ : Phase II trial of bevacizumab in the treatment of persistent or recurrent squamous cell carcinoma of the cervix : a gynecologic oncology group study. J Clin Oncol 27(7) : 10691074,2009 